\title{
EXPERIENCIA CLÍNICA
}

\section{Malaria por Plasmodium falciparum en el servicio de medicina del Hospital San Camilo de San Felipe}

\author{
GONZALO WILSON*, ENRIQUE CAMPONOVO**, PATRICIA NEIRA*, \\ BENJAMÍN SUBERCASEUX* y NELSON MUÑOZ*
}

\section{MALARIA BY Plasmodium falciparum IN THE MEDICINE SERVICE OF SAN CAMILO HOSPITAL OF SAN FELIPE}

\begin{abstract}
We present a case report of a male patient of 36 years old, truck driver, with out any morbid history, that after a travel to Amazonian region of Brazil, by truck, start with fever, malaise, joint pain. He consulted to the Emergency Room of a General Hospital in Los Andes (Chile,) after one week of illness. In the hospital it was quantified the fever, and it was found the liver enzymes increased, with anaemia and platelets diminished. He was transferred to the hospital of San Felipe, because it was thought that he could need some support measures of Intensive Care Unit. With the epidemiological history of the patient It was suspected the diagnosis of Malaria, so a thick and a thin smear were performed, and indirect tests also ( $p L D H$ by the optiMAL Test kit), in the Public Health Institute, that confirmed the diagnosis of Malaria by Plasmodium falciparum. He was treated with Chloroquine in the recommended regimen, with clinical improvement. Malaria by $\boldsymbol{P}$. falciparum is described as the one with more hepatic and haematological compromise, and with high parasitic index in blood. With the improvements in travelling, to endemic regions, the risk of appearance of malaria cases in non endemic areas is increasing, as the reported case. So the health network must be prepared to manage this cases, and to have a close contact with the reference laboratory, to send the samples and to notify the cases. In the case, the diagnosis was made in a quick way, thanks to the anamnesis and the clinical suspicious.
\end{abstract}

Key words: Malaria, Plasmodium falciparum, Case report.

\section{CASO CLÍNICO}

Paciente de 36 años, brasileño, de profesión camionero, que por motivo de su trabajo debe efectuar viaje por tierra al Matto Grosso, a la ciudad de Manaos, en el mes de Julio del 2004 permaneciendo en esa área por cerca de 20 días.
Durante ese tiempo no recibe ningún tipo de quimioprofilaxis, no empleó mosquitero al dormir, y ningún tipo de repelente de insecto.

Consulta el día 10 de Agosto del 2004 al Servicio de Urgencia del Hospital de los Andes, por cuadro de compromiso del estado general, sensación febril y "estar amarillo" (ictericia), sin

Cátedra de Parasitología, Dpto. de Preclínicas, Escuela de Medicina, Universidad de Valparaíso.

** Servicio de Medicina, Hospital San Camilo de San Felipe. 
vómitos ni diarrea. Este cuadro lo presentaría desde el día 07 de Agosto, y no había consultado por estar en ruta hacia Chile.

$\mathrm{Al}$ ingreso presenta taquicardia de 104 latidos por minuto, normotenso, temperatura en axila de $38,7^{\circ} \mathrm{C}$, y al examen físico destaca una marcada ictericia. Se le solicitan exámenes donde presenta un recuento de leucocitos elevados, Bilirrubina Total elevada al igual que la directa, con una anemia normocítica y normocrómica. Se plantea el diagnóstico de Síndrome Febril Ictérico Obs: Hepatitis viral / Fiebre Amarilla / Malaria. Y se indica hidratación parenteral, medidas físicas antipiréticas y Metamizol $1 \mathrm{~g}$ cada 8 horas (endovenoso).

Ante un eventual agravamiento del paciente, se decide el traslado, durante la noche del 10 al 11 de Agosto, a la UCI del Hospital San Camilo de San Felipe. Aquí se mantienen las indicaciones antipiréticas, evoluciona febril, manteniéndose hemodinámicamente estable, sin requerir un manejo más invasivo.

El día 11 de Agosto se traslada a sala de pacientes agudos, y aquí se le repiten varios exámenes, mostrando: una caída del hematocrito $(30,7 \%)$ y los leucocitos (3.700), con abundantes formas juveniles (baciliformes), y una trombocitopenia de 23.000. Se interroga dirigidamente al paciente por factores sugerentes o de riesgo de malaria, siendo su anamnesis muy orientadora, dado que agrega que su compañero de viaje también había sido diagnosticado Malaria una semana atrás, y se encontraba en ese momento hospitalizado en Brasil. Ante esto se coordina con el Instituto de Salud Pública (Laboratorio de Referencia de Parasitología) para el envío de frotis y muestra de sangre para exámenes complementarios indirectos. Se envían muestras ese mismo día a mediodía, obteniendo el resultado en la tarde, confirmando el diagnóstico de Malaria por $P$. falciparum, por medio de visualización al frotis y del kit optiMAL IT (prueba indirecta que detecta la enzima pLDH, específica de $P$. falciparum).

En forma paralela se enviaron cinco frotis a la Cátedra de Parasitología de la Escuela de Medicina de la U. de Valparaíso, donde se visualizaron elementos compatibles con el diagnóstico.

Ante el diagnóstico de certeza se inició terapia específica el día 12 de Agosto del 2004, en base a Cloroquina (por falta de disponibilidad de otro fármaco en ese momento): en dosis $600 \mathrm{mg}$ cada 12 horas el primer día y luego $600 \mathrm{mg}$ al día por dos días más. El paciente evoluciona con estabilización de su hematocrito y recuento de plaquetas y volviéndose afebril el día 14/08/04. El día 17 de Agosto presenta un nuevo pick febril hasta $38^{\circ} \mathrm{C}$, bien tolerado, y al examen físico se pesquisa una flebitis braquial izquierda, en relación a un punto de punción (fleboclisis), que se trató con Cloxacilina $500 \mathrm{mg}$ cada 6 horas y frío local, respondiendo favorablemente, volviéndose afebril a las 24 horas. El paciente es trasladado por vía aérea a Brasil, el día 20 de Agosto, para completar el seguimiento y estudio. (Tabla 1; Figura 1).

Tabla 1. Exámenes de Laboratorio

\begin{tabular}{|c|c|c|c|c|c|c|c|}
\hline Fecha & $10 / 08$ & 11/08 & $12 / 08$ & $13 / 08$ & $16 / 08$ & 17/08 & $18 / 0$ \\
\hline Hematocrito $(\%)$ & 35,7 & 30,7 & 30,4 & 30,2 & 30,6 & 29 & 29 \\
\hline Leucocitos & 14.400 & 3.700 & 3.200 & 4.500 & 3.400 & & 3.000 \\
\hline Plaquetas & 31.000 & 23.000 & 38.000 & 70.000 & 69.000 & & 78.800 \\
\hline Proteína C Reactiva & 53,95 & & & & 84,6 & & 65,9 \\
\hline $\mathrm{SGOT}^{1}$ & 696 & & & 201 & & 26 & \\
\hline SGPT $^{2}$ & 403 & & & 395 & & 77 & \\
\hline Bilirrubina total & 7,57 & & & 1,87 & & 0,98 & \\
\hline Bilirrubina directa & 5,56 & & & 1,21 & & 0,65 & \\
\hline Creatinina & 1,20 & & & 1,21 & 0,84 & 0,98 & \\
\hline
\end{tabular}

1: SGOT Serum glutamic oxaloacetic transaminase.

2: SGPT Serum glutamic pyruvic transaminase. 


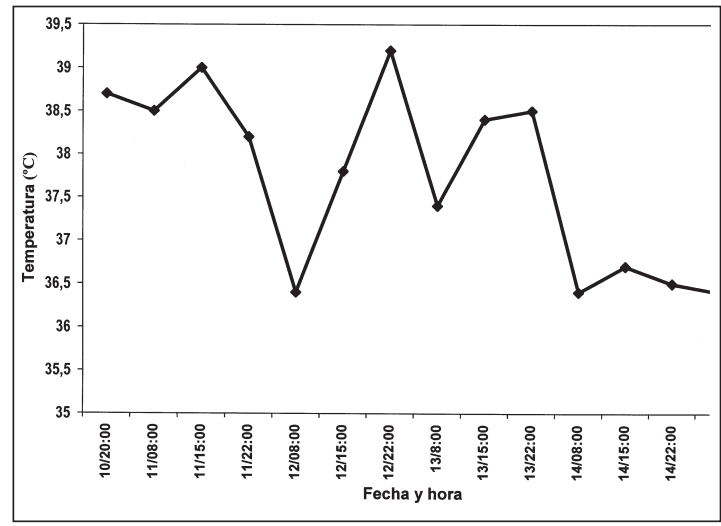

Figura 1. Evolución de la curva febril del paciente.

\section{DISCUSIÓN}

La malaria es una enfermedad ocasionada por la infección de los parásitos $P$. falciparum, $P$. vivax, $P$. ovale y/o P. malariae, por medio de la picadura del mosquito hembra del género Anopheles. Esta patología es de gran incidencia a nivel mundial, con aproximadamente 500 millones de nuevos casos al año a nivel mundial, con una mortalidad estimada de 500 mil a 2 millones al año, esto en las naciones endémicas con una mayor concentración en centro de África y Sudeste Asiático ${ }^{1}$. Pero, en nuestro país el mosquito fue erradicado de Chile a mediados del siglo 20, y los casos nuevos son generalmente importados de regiones endémicas, como el caso previamente descrito ${ }^{2}$.

El insecto infectado pica al hombre, inyectando esporozoitos, los cuales llegan al hígado donde invaden los hepatocitos, luego liberando merozoitos a la circulación sanguínea, lo cual provoca la respuesta inflamatoria generalizada, dado por la gran liberación de citoquinas, y posteriormente invadiendo a los eritrocitos, y luego de varias etapas llegan a gametogonia, los cuales son succionados por el mosquito. La fertilización ocurre en el tracto intestinal del Anopheles, y de ahí se forma un ooquiste, y luego ooquinetos y posteriormente se forman los esporozoitos, los cuales invaden todo el cuerpo del insecto, incluyendo las glándulas salivales, por donde ingresan al cuerpo humano ${ }^{1-3}$.

La clínica de la enfermedad se caracteriza por un cuadro de mialgias, decaimiento y que rápidamente se pasa a un cuadro febril intenso
(39 a $40^{\circ} \mathrm{C}$ ), y gran compromiso general, esto asociado a ictericia, alteraciones de la Pruebas Hepáticas, Anemia (secundaria tanto a la hemólisis secundaria al parásito como a la sepsis secundaria) y trombocitopenia, siendo estas últimas más características de $P$. falciparum $^{3}$.

Cada protozoo posee comportamientos en la clínica muy particulares, donde destaca que el $P$. falciparum, en general, como el que da una enfermedad mayor gravedad, con compromiso del sistema nervioso central: Malaria Cerebral (convulsiones, compromiso de conciencia, y coma), gran repercusión hepática, anemia y trombocitopenia muy marcada, y siendo la de mayor letalidad en comparación a las otras especies; pero que raramente deja portadores crónicos, en cambio la por $P$. vivax, la por $P$. malariae, y la por $P$. ovale dan formas más benignas, pero muchas veces cuando no son adecuadamente tratados quedan portadores asintomáticos, en especial las dos primeras especies, con posibilidades de recidivas en situaciones de inmunocompromiso o "stress" 4 .

Para el diagnóstico de certeza, debe visualizarse al protozoo en la sangre y/o intraeritrocitario, lo cual requiere de un entrenamiento adecuado. Pero existen métodos indirectos, como es la detección de $\mathrm{pLDH}$, específico para identificar $P$. falciparum, método existente en kits comerciales, los cuales son recomendados para laboratorios de áreas no endémicas ${ }^{5,6}$.

Existen diversos esquemas de tratamientos, dependiendo de la especie de protozoo que se trate. Pero también en los últimos 20 años se han descrito zonas endémicas de malaria, en donde existe resistencia por parte del coccidio a las terapias habituales, lo cual ha obligado ha desarrollar nuevos esquemas específicos para zonas resistentes. En general las terapias son de forma oral, pero hay esquemas parenterales, para los casos de mayor gravedad ( $P$. falciparum). Dado la gran morbilidad y las repercusiones de la parasitosis, se han creado esquemas de terapias quimioprofilácticas, para las personas que viajan de regiones no endémicas a áreas endémicas. Otras medidas de prevención son individuales como: empleo de mosquitero en la cama, usar ropa de manga larga y que cubran las piernas en las horas nocturnas y en la tarde (crepúsculo) como también ropas impregnadas de permetrina, no acercarse a zonas de aguas estancas o quietas, y/o emplear repelentes de insectos (DEET igual 
o mayor al 35\%) adecuados en las horas de día y noche ${ }^{6}$.

Se debe tener presente que no se debe tratar un paciente sospechoso de Malaria sin el diagnóstico de certeza, en regiones no endémicas, y que en nuestro país el centro de referencia para su diagnóstico Laboratorio de Parasitología del Instituto de Salud Pública (ISP). Esto dado a que en general no existe mucha experiencia en los laboratorios clínicos nacionales para identificar al Plasmodium de forma rutinaria, y podrían darse falsos positivos o errar al diagnóstico de la especie, lo cual conllevaría un error en la elección de tratamiento.

En las últimas décadas ha existido un gran aumento en los viajes, desde y hacia nuestra zona, lo cual ha hecho aparecer enfermedades no habituales a esta región. Y que están afectando a centro médicos más pequeños o periféricos de la red de salud, como es el Hospital San Camilo, perteneciente a un Servicio de Salud fronterizo, y muy cercano a la ruta internacional con Argentina. Lo cual lo hace muy susceptible de ser punto de aparición de casos índices, y debe existir una comunicación expedita con los especialistas y laboratorios adecuados para el diagnostico y la confirmación de la infección, y su posterior tratamiento.

En este caso, la hipótesis diagnóstica se realizó principalmente en base a la anamnesis con el paciente, y que a una rápida y ágil coordinación con el centro de referencia. Lo cual llevó finalmente a obtener un resultado de certeza en menos de 12 horas. Lo cual logró demostrar un adecuado sistema de red de los laboratorios de distintos Servicios de Salud. El tratamiento se hizo en base a lo recomendado por CDC (Centro de Control y Prevención de Enfermedades, EEUU), iniciando un esquema con Cloroquina por disponibilidad rápida del fármaco, se inicio esquema para $P$. falciparum sensible a Cloroquina, obteniendo buena respuesta, lo que hace pensar en que la cepa era sensible a dicho fármaco, a pesar de que en la región del Matto Grosso existe $P$. falciparum resistente a Cloroquina $^{4,5}$.

\section{RESUMEN}

Paciente de 36 años (camionero), sin antecedentes mórbidos de importancia, que luego de un viaje por Brasil, inicia cuadro de malestar general, poliartralgia y gran decaimiento. Consultando a la semana por sensación febril e ictericia en el Hospital de los Andes. Se constata fiebre, compromiso del estado general, ictericia, destacando en los exámenes de laboratorio: elevación de las transaminasas, fosfatasas alcalinas, hiperbilirrubinemia y disminución de hematocrito y plaquetas. Se lo hospitaliza con el diagnóstico de Síndrome Febril Ictérico Obs: Hepatitis viral, malaria o fiebre amarilla. Evoluciona con caída de su hematocrito y plaquetas, manteniéndose las pruebas hepáticas alteradas. Se realizan exámenes directos e indirectos para diagnóstico de Malaria, confirmándose con la visualización de trofozoítos de Plasmodium falciparum e indirectamente por detección en sangre de pLDH mediante optiMAL IT kit. Se inicia terapia con Cloroquina, con buena respuesta sintomática, con recuperación de plaquetas, mantención del Hematocrito y normalización de las pruebas hepáticas.

La malaria por $P$. falciparum se describe como aquella que ocasiona las formas más graves y con compromiso hepático. Se destaca que ante la facilidad de transporte de personas de áreas endémicas, se hace más factible la aparición de casos en áreas no endémicas como en este servicio. Debido al riesgo, se debe estar preparado para la toma de muestras adecuadas que permitan la certificación en centros que como en éste, llegan pacientes extranjeros. El diagnóstico del paciente se hizo de forma expedita debido a una buena anamnesis, la que orientó claramente al diagnóstico de certeza.

\section{REFERENCIAS}

1.- MURRAY P, KOBAYASHI G. Microbiología Médica. $2^{\circ}$ Edición Ed. Harcourt Brace, Madrid España 1997.

2.- SUBERCASEUX B, NEIRA P. Apuntes de Parasitología Práctica. Ed. Universidad de Valparaíso, Valparaíso Chile, 1993; 115-7.

3.- ECHEVARRIA J, LLANOS A. Infecciones tropicales en viajeros a Latinoamérica. Rev Chil Infectol 2000: 17: 25-33.

4.- ATIAS A. Parasitología Clínica. 20 Edición, Ed. Mediterráneo, Santiago Chile 1998. 223-41.

5.- WELLERM T, MILLER L. Two worlds of malaria. $\mathrm{N}$ Eng J Med 2003: 349: 1496-8.

6.- WHITE N. The treatment of malaria. N Eng J Med 1996, 335: 800-6. 